\title{
INFORMATION TECHNOLOGY GOVERNANCE OF JAPANESE COMPANIES; AN EMPIRICAL STUDY
}

\author{
Michiko Miyamoto \\ Department of Management Science and Engineering, \\ Akita Prefectural University, Yurihonjo City Akita, Japan
}

\begin{abstract}
IT has become an essential part of the organization. IT governance specifies the decision rights and accountability framework to encourage desirable behaviour in using IT. Concepts of IT governance has expanded to improve IT-business alignment under today's business environment and prospects. This paper contributes to empirically knowledge of IT governance practices in Japanese organizations based on survey data gathered from 101 corporations, including large, medium, and small companies. The findings of the ordinal regression analyses in this study indicate that IT governance is associated with Strategic Alignment, Performance Measurement and Value Delivery, while Risk Management and Resource Management have positive but no significance association with IT governance.
\end{abstract}

\section{KEYWORDS}

IT Governance, IT-Business Alignment, Strategic Alignment Maturity, Regression Analysis.

\section{INTRODUCTION}

According to the "Corporate IT Trend Survey 2020" (FY2019 survey) by Japan Users Association of Information Systems [1] , which examines trends in corporate IT investment and IT strategy, $40.7 \%$ of the total answered their IT budgets would "increase", $46.0 \%$ "unchanged", and 13.2\% "decrease." Digital transformation in business continues to be an important management issue. The role of IT continues to grow, and IT budgets are expected to continue their upward trend despite growing economic uncertainty.

Today, IT has become an essential part of the organization, and IT function of the organization has evolved from a technology provider into a strategic partner [2]. IT governance addresses the authority and control for key IT activities in organizations, such as IT infrastructure and IT use. Effective IT governance guarantees that IT helps business goals, maximizes investment in IT, and directs IT-related risks and opportunities [3]. A lack of IT governance in one company can threat an entire society, as shown by two well-publicized IT failures in Japan: Japan Airlines' halting automated check-in procedures by the system failure, and Mizuho Financial Group's banking system failure. Those system failures caused chaos, from which the recovery took for a while until the operations went completely back to normal.

Weill and Ross [4] define IT governance as specifying the decision rights and accountability framework to encourage desirable behaviour in using IT. In corporate management, IT governance, which is an organizational mechanism for continuously optimizing IT investment,

David C. Wyld et al. (Eds): CCSIT, SIPP, PDCTA, AISC, NLPCL, BIGML, NCWMC - 2021

pp. 29-40, 2021. CS \& IT - CSCP 2021

DOI: $10.5121 /$ csit.2021.110704 
effects, and risks, can be the most important issue for Japanese companies. IT governance influences corporate management strategy. Concepts of IT governance has expanded [3][4] to improve IT-business alignment under today's business environment and prospects.

This paper contributes to the empirical knowledge of IT governance practices in Japanese organizations by using a questionnaire survey data. Factor analyses and multiple regression have been used to interpret the relationships among IT governance and IT governance related factors.

The remainder of this paper is organized as follows. Section 2 presents a literature review of the concept of IT governance, IT governance framework, strategic alignment maturity, and IT governance in Japan. Section 3 describes research objectives and hypotheses. Section 4 presents the methodology used for questionnaire survey and multivariate statistical approach. Section 5 presents our survey results and implications. The conclusion is presented in Section 6.

\section{LiterATURE REVIEW}

IT governance takes place through the specification of decision rights and accountabilities framework designed to motivate advantageous IT-related behaviour within an organization [4]. IT management must ensure the governance mechanisms are in place implemented to fulfil the strategies [5]. Many literatures have conducted a systematic literature review on IT governance and listed various definitions (e.g. [6] [7] [8] [9] [10]).

Carroll, et al [6] focused on the published literature on the control objective for information and related technology (COBIT). COBIT and "value from IT investments" (Val IT) are frameworks developed by Information Systems Audit and Control Association (ISACA) for information technology (IT) management and IT governance to help business executives, IT personnel and management. They found approximately $7 \%$ of the publications had academic background, while $93 \%$ were practitioners oriented. Even the later study by De Maere and De Haes [11] suggested the number of publications in top journals is low at $1 \%$ within the context of IT governance.

Based on their literature review, Vejseli and Rossmann [8] identified five relevant perspectives for further research including strategic alignment perspective, IT leadership perspective, IT capability and process performance perspective, resource relatedness perspective and culture perspective. Fink and Ploder [12] introduced a decision support framework to address the issue of implementing IT governance into the organizational context and imply corporate culture can influence the success of IT governance implementation. Their model is developed based on the IT governance model suggested by Weil and Ross [4] with its five decision fields: IT principles, IT architecture, IT infrastructure, business applications, IT investment and prioritization. Webb et al. [7] proposed definitive definition of IT governance, focusing on two important areas of influence on the emergence of IT governance: 1) corporate governance within organization and 2) strategic information system. They found five elements (strategic alignment, delivery of business value through IT, performance management, risk management and control and accountability) of the framework have been validated.

Aasi et al. [10] found that IT governance is strongly linked with the corporate governance, which is influenced by culture; however, there are few research studies in this topic. After performing an extensive literature review, Levstek et al. [9] decided to use the following definition of De Haes and Van Grembergen [13] as the most comprehensive definition.

"IT governance is an integral part of corporate governance, exercised by the Board, overseeing the definition and implementation of processes, structures and relational mechanism in the 
organization that enable both business and IT people to execute their responsibilities in support of business/IT alignment and the creation of business value from IT enabled business investment" (see Figure 1).

Symons et al. [14] suggested that implementing a good IT governance requires a framework based on structure, process, and communication. Symons et al. [14] also suggests that there are four objectives that drive IT governance: IT value and alignment, accountability, performance measurement, and risk management. Each of these objectives must be addressed as part of the IT governance process (see Figure 2).

There are many theoretical literatures, discussing over different definitions of IT governance and frameworks, while fewer empirical studies are found.

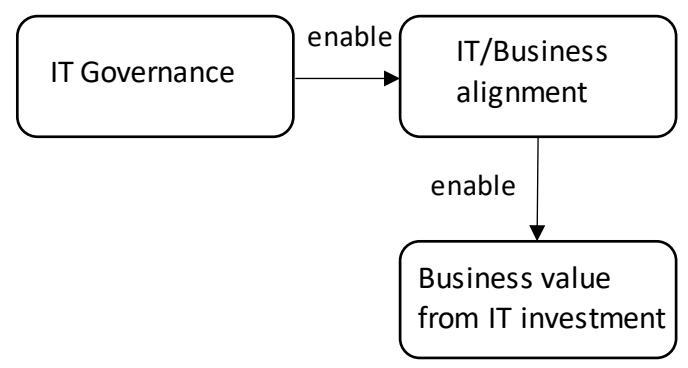

Figure 1. The definition of IT Governance

(Source: De Haes \& Van Gembergen [11])

Lunardi et al. [15] empirically tested the determinants for the effectiveness of IT governance, based on survey data of 87 CIOs of large Brazilian companies. They found that IT strategic alignment, IT value delivery, IT risk management and IT performance management are positive and significant associated to IT governance effectiveness, indicating that the higher the performance of these domains, the higher the IT governance effectiveness. IT strategic alignment, in turn, appears as the main predictor. Miyamoto and Kudo [16] conducted an empirical research on IT governance using research data of 345 SMEs residing in Akita prefecture, located in the northern part of Japan. They found that Strategic Alignment, Performance Measurement, Resource Management, Risk Management, Value Delivery are positive and significant associated to IT governance. They also found that most of these SMEs understand the importance of IT governance, but few have a person in charge of IT specialization.

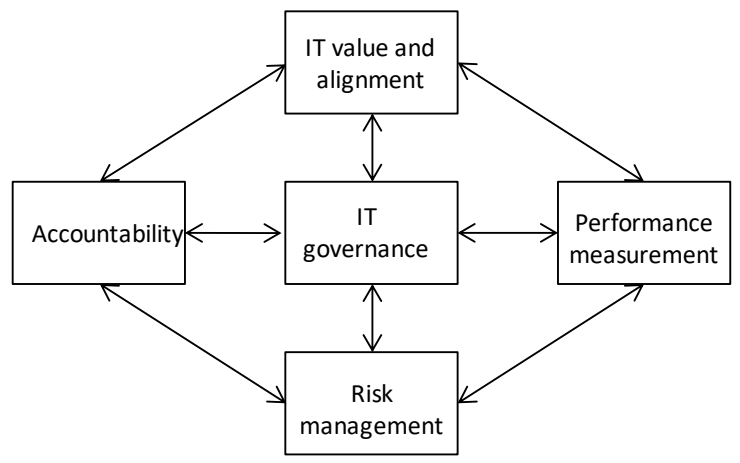

Figure 2. Four objectives that drive IT governance [14] 


\section{RESEARCH MODEL AND HYPOTHESES}

The proper alignment between use of IT and the business goal of an organization is basic principal to efficient and effective IT governance [6]. Based on literature review, the author assesses Japanese corporations' IT governance by strategic alignment, risk management, value delivery, resource management, and performance management, and created a research model (see Figure 3).

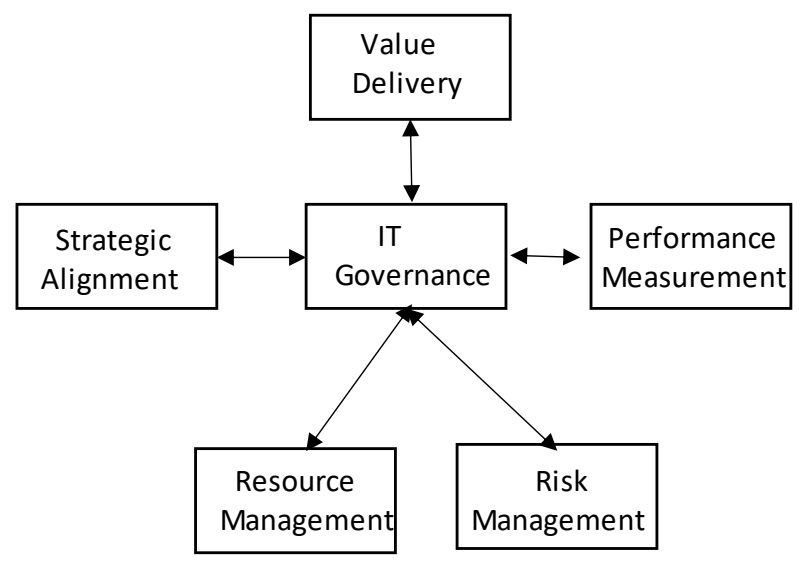

Figure 3. Research model

The following hypotheses are proposed and are examined.

H1: There is a significant, positive relationship between IT governance and Strategic Alignment.

H2: There is a significant, positive relationship between IT governance and Performance Measurement.

H3: There is a significant, positive relationship between IT governance and Resource Management.

H4: There is a significant, positive relationship between IT governance and Risk Management.

H5: There is a significant, positive relationship between IT governance and Value Delivery.

\section{SURVEYS}

\subsection{Data}

The data were collected by means of a questionnaire. The survey was conducted throughout Japan from late August in 2018 to mid-November in 2018. Respondents were randomly selected from several databases of local businesses of each prefecture and from members of Japan Users Association of Information Systems. The survey was conducted online and amassed 101 valid responses. The questionnaire was sent by email to the information system division, as well as the corporate planning division of the firms. Most of the questionnaires are asked by 5 -point scale. 
Table 1. Size of the companies studied

\begin{tabular}{|l|r|l|r|}
\hline \multicolumn{2}{|c|}{ Total number of employees } & \multicolumn{2}{c|}{ Annual Revenue (in billion yen) } \\
\hline More than 1,000 & 27 & More than 50 & 25 \\
\hline $300-1,000$ & 24 & $30-50$ & 10 \\
\hline $100-300$ & 14 & $10-30$ & 14 \\
\hline $50-100$ & 10 & $5-10$ & 4 \\
\hline $20-50$ & 13 & $0.5-5$ & 27 \\
\hline Less than 20 & 12 & Less than 0.5 & 18 \\
\hline Missing & 1 & Missing & 3 \\
Total & 101 & Total & 101 \\
\hline
\end{tabular}

Table 1 shows number of employees and annual revenue of the sample. The data in this study contains both large corporations as well as SMEs. In Japan, SMEs is defined under Article 2, Paragraph 1 of the Small and Medium-sized Enterprise Basic Act, and the term "small enterprises" refers to "small enterprises" as defined under Article 2, Paragraph 5 of said act. The category of "more than 1,000 employees" and "300 to 1,000 employees" can be considered as large corporations: those of up to 300 employees as small and medium enterprises, and those less than 20 employees as small enterprises.

The respondents in this study represented a variety of industry. The list of industries for those participating this research is shown in Table 2 and the list of variables is shown in Table 3.

Table 2. The Participating Organizations: Industries

\begin{tabular}{lrr}
\hline Industries & Frequencies & $\%$ \\
\hline Rubber / ceramic industry & 2 & 2.0 \\
Other service industry & 8 & 7.9 \\
Other manufacturing indus try & 10 & 9.9 \\
Chemical · Petroleum & 1 & 1.0 \\
Machinery and electrical equipment & 14 & 13.9 \\
Eucation & 2 & 2.0 \\
Finance / insurance industry & 1 & 1.0 \\
Construction & 8 & 7.9 \\
Trading company · other wholes ale busines s & 8 & 7.9 \\
Retail $\cdot$ Food industry & 5 & 5.0 \\
Telecommunications & 24 & 23.8 \\
Food & 3 & 3.0 \\
Fis heries $\cdot$ Agriculture $\cdot$ Forestry $\cdot$ Mining & 1 & 1.0 \\
Precision equipment & 2 & 2.0 \\
Fiber & 2 & 2.0 \\
Warehouse $\cdot$ Trans portation & 1 & 1.0 \\
Steel $\cdot$ Nonferrous metal $\cdot$ Metal & 2 & 2.0 \\
Electricity, Gas and Public Service & 2 & 2.0 \\
Real estate busines s & 2 & 2.0 \\
Transportation equipment & 3 & 3.0 \\
\hline Total & 101 & 100.0 \\
\hline & &
\end{tabular}




\subsection{Empirical Analyses}

The ordinal regression model [17] is used to model between the ordinal outcome and independent variables. Both dependent variables (IT governance (ITG) and independent variables (Strategic Alignment (SG), Risk Management (RM), Value Delivery (VD), Resource Management (RM), Performance Management (PM) are obtained by confirmatory factor analysis.

\subsubsection{Confirmatory Factor Analysis}

In the social sciences, factor analytical methods are commonly used in the scale measurement in examining the structure of scales. There are two common standard statistical tools, exploratory and confirmatory factor analyses for developing measurement scales.

Confirmatory factor analysis (CFA) is a multivariate statistical procedure that is used to test how well the measured variables represent the number of constructs. In CFA, the number of factors requires in the data can be specified, and measured variable is related to which latent variable.

The basic factor analysis equation can be represented in matrix form as:

$$
Z=\lambda F+\varepsilon
$$

Where $\mathrm{Z}$ is a px1 vector of variables, $\lambda$ is a pxm matrix of factor loadings, $\mathrm{F}$ is an $\mathrm{mx} 1$ vector of factors and $\varepsilon$ is a px1 vector of error or residual (unique or specific) factors [18]. Because of differences in the units of variables used in factor analysis, the variables were standardized, and a correlation matrix of variables was used to obtain eigenvalues. Varimax rotation was used to facilitate interpretation of factor loadings $\left(L_{i k}\right)$. Factor coefficients $\left(C_{i k}\right)$ were used to obtain factor scores for selected factors. Factors with eigenvalues greater than 1 were employed in multiple regression analysis [18] [19] [20]. Score values of selected factors were considered as independent variables for predicting IT governance. 
Table 3. A List of Variables

Variables

importance a) Importance of leveraging IT for enhancing competitiveness

top $1 \quad$ c) Involvement of IT personnel to process business strategy.

top2 d) Involvement of senior management to IT strategy formulation process

Strategic

top3 e) Involvement of senior management for business transformation projects involving IT

Alignment

top4 f) Aggressiveness of management for communication with IT personnel

top5 g) Senior management's IT strategy is known to every employee.

top6 h) Management suggests and supports utilization of IT in business

\begin{tabular}{lll} 
& top6 & h) Management suggests and supports utilization of IT in business \\
\hline & risk1 & a) Managers communicate with IT personals to understand the circumstances of their use of IT \\
risk2 & b) IT personnel substantively understand the management strategy \\
Risk & risk3 & c) The business unit personnel understand IT environment and the company's IT strategy \\
Management & risk4 & $\begin{array}{l}\text { d) Exchanging ideas between departments by leveraging information sharing and corporate } \\
\text { intranet groupware }\end{array}$
\end{tabular}

risk5 e) Hold regular meetings on IT projects

gove1 a) Supervision and management of IT budget

gove2 b) Supervision and management of IT investment evaluation

gove3 c) Thorough sharing duties and authority on IT

IT governance gove4 $\quad$ d) Establishment of the IT-related committee

gove5 e) Clarification of the criteria in an allocation and prioritization of IT utilized resources

gove6 f) Standardization of IT adoption process

gove7 g) IT security risk management and supervision

value $1 \quad$ a) Understanding the business value expected in the use of IT between business sectors

value $2 \quad$ b) Participation in the implementation process of IT employees

value $3 \quad$ c) Participation in the management planning process of IT personnel

Value Delivery value4 $\quad$ d) Each department and senior management to share each other's goals and risk

value5 e) Business divisions and IT personnel trust each other

value6 f) Regarding IT projects, consult professionals (such as the IT coordinator) or external organizations, such as public institutions and private companies.

\begin{tabular}{|c|c|c|}
\hline \multirow{6}{*}{$\begin{array}{l}\text { Performance } \\
\text { Management }\end{array}$} & skill1 & $\begin{array}{l}\text { a) Encourage and offer a chance to take advantage of in-house IT employees to create new ways } \\
\text { to use IT }\end{array}$ \\
\hline & skill2 & b) Educate and train to increase the capacity utilization of IT \\
\hline & skill3 & c) Set a goal of IT skills of employees and recommend employees to take the IT related exam \\
\hline & skill4 & d) Hiring personnel with the knowledge and skills required for the IT management and operation \\
\hline & skill5 & e) Creating managerial posts for IT professionals \\
\hline & skill6 & f) Expanding the career paths for IT professionals \\
\hline \multirow{9}{*}{$\begin{array}{l}\text { Resource } \\
\text { Management }\end{array}$} & resource1 & $\begin{array}{l}\text { a) Computerize general administrative duties (e.g., planning, finance, accounting, regulatory } \\
\text { measures, and quality control) }\end{array}$ \\
\hline & resource 2 & $\begin{array}{l}\text { b) Computerize personnel and labor management (e.g., human resources management and } \\
\text { benefits, recruitment and training of personnel, salaries payments, etc.) }\end{array}$ \\
\hline & resource 3 & $\begin{array}{l}\text { c) Computerize technological development (e.g., R \& D, product design, knowledge management, } \\
\text { and production equipment design) }\end{array}$ \\
\hline & resource 4 & d) Computerize procurement (e.g., demand planning, payment and billing, procurement, etc.) \\
\hline & resource 5 & $\begin{array}{l}\text { e) Computerize purchasing and logistics (e.g., scheduling, shipment and delivery planning, } \\
\text { warehouse management, inventory management, etc.) }\end{array}$ \\
\hline & resource6 & $\begin{array}{l}\text { f) Computerize manufacturing operations (e.g., assembly, maintenance, equipment, equipment } \\
\text { maintenance, inspection, printing, etc.) }\end{array}$ \\
\hline & resource7 & $\begin{array}{l}\text { g) Computerize logistics shipping (e.g., order processing, shipping and transportation planning of } \\
\text { the final product, and storage of the final product) }\end{array}$ \\
\hline & resource8 & h) Computerize marketing and sales (e.g., advertising, sales, promotion, etc.) \\
\hline & resource 9 & $\begin{array}{l}\text { i) Computerize servicing (e.g., maintenance and repair of the final product, management and } \\
\text { customer support) }\end{array}$ \\
\hline
\end{tabular}


Table 4. A Correlations Matrix

\begin{tabular}{lcrrrrr}
\hline & $\begin{array}{c}\text { Strategic } \\
\text { Alignment }\end{array}$ & $\begin{array}{c}\text { Risk } \\
\text { Management }\end{array}$ & $\begin{array}{c}\text { IT } \\
\text { Governance }\end{array}$ & $\begin{array}{c}\text { Value } \\
\text { Delivery }\end{array}$ & $\begin{array}{c}\text { Resource } \\
\text { Management }\end{array}$ & $\begin{array}{c}\text { Performance } \\
\text { Management }\end{array}$ \\
\hline Strategic Alignment & 1 & $.818^{* *}$ & $.775^{* *}$ & $.743^{* *}$ & $.334^{* *}$ & $.666^{* *}$ \\
Risk Management & $.818^{* *}$ & 1 & $.786^{* *}$ & $.759^{* *}$ & $.417^{* *}$ & $.698^{* *}$ \\
IT Governance & $.775^{* *}$ & $.786^{* *}$ & 1 & $.830^{* *}$ & $.419^{* *}$ & $.729^{* *}$ \\
Value Delivery & $.743^{* *}$ & $.759^{* *}$ & $.830^{* *}$ & 1 & $.338^{* *}$ & $.613^{* *}$ \\
Resource Management & $.334^{* *}$ & $.417^{* *}$ & $.419^{* *}$ & $.338^{* *}$ & 1 & $.475^{* *}$ \\
Performance Management & $.666^{* *}$ & $.698^{* *}$ & $.729^{* *}$ & $.613^{* *}$ & $.475^{* *}$ & 1 \\
\hline${ }_{* *}^{* *}$ Correlation is significant at the 0.01 level (2-tailed). & & & & &
\end{tabular}

Table 4 contains the Pearson correlation coefficient between all pairs of six latent variables obtained by factor analysis. Correlation is significant at the 0.01 level (two-tailed) and the correlations between indicators range between 0.33 and 0.83 . All variables are correlated with other variables well, but none of the correlation coefficients is particularly larger than 0.90; therefore, multicollinearity is not a problem for these data.

\subsubsection{Regression Analysis}

The regression equation fitted was:

$$
I T G_{i j}=a+b_{1} S A+b_{2} R M+b_{3} V D+b_{4} R M+b_{5} P M+e
$$

Where $a$, is regression constant (it is the value of intercept and its value is zero); $b_{1}, \ldots b_{5}$, are regression coefficients of Factor Scores (FS), and $e$ is the error term. Regression coefficients were tested with a t-statistic. The coefficient of determination (R2) was used as an indicator of the quality of the regression [21].

\section{EMPirical RESUltS}

The results of analyses are shown as follows.

Table 5. Model Summary

\begin{tabular}{|c|c|c|c|}
\hline $\mathrm{R}$ & $\mathrm{R}$ Square & $\begin{array}{c}\text { Adjusted } \mathrm{R} \\
\text { Square }\end{array}$ & $\begin{array}{c}\text { Std. Error of the } \\
\text { Estimate }\end{array}$ \\
\hline $.880^{\mathrm{a}}$ & .775 & .762 & .44616271 \\
\hline
\end{tabular}

The table 5 is the model summary. $\mathrm{R}$ can be considered as one measure of the quality of the prediction of the dependent variable, IT governance. A value of 0.880 indicates a good level of prediction. The $\mathrm{R}$ square $\left(R^{2}\right)$ value, the coefficient of determination, shows the value of 0.775 , which indicates the independent variables explain $77.5 \%$ of the variability of the dependent variable.

Table 6. ANOVA

\begin{tabular}{|l|l|r|r|r|r|r|}
\hline \multicolumn{2}{|l|}{ Model } & Sum of Squares & df & Mean Square & F & \multicolumn{1}{c|}{ Sig. } \\
\hline \multirow{3}{*}{1} & Regression & 62.932 & 5 & 12.586 & 63.229 & $.000^{\mathrm{b}}$ \\
\cline { 2 - 7 } & Residual & 18.314 & 92 & .199 & & \\
\cline { 2 - 7 } & Total & 81.245 & 97 & & & \\
\hline
\end{tabular}


The F-ratio in the ANOVA (Table 6) tests whether the overall regression model is a good fit for the data. The table shows that the independent variables statistically significantly predict the dependent variable, $\mathrm{F}(5,92)=63.229, \mathrm{p}(.001)<0.05$ (i.e., the regression model is a good fit of the data).

Table 7 shows the results of regression analyses.

Table 7. Coefficients

\begin{tabular}{|c|c|c|c|c|c|c|}
\hline & & \multicolumn{2}{|c|}{$\begin{array}{c}\text { Unstandardized } \\
\text { Coefficients } \\
\end{array}$} & \multirow{2}{*}{\begin{tabular}{|c|}
$\begin{array}{c}\text { Standardized } \\
\text { Coefficients }\end{array}$ \\
Beta \\
\end{tabular}} & \multirow[b]{2}{*}{$\mathrm{t}$} & \multirow[b]{2}{*}{ Sig. } \\
\hline \multicolumn{2}{|c|}{ Model } & $\mathrm{B}$ & Std. Error & & & \\
\hline \multirow[t]{6}{*}{1} & (Constant) & -.001 & .045 & & -.016 & .987 \\
\hline & Strategic_Alignment & .149 & .087 & .153 & 1.719 & .089 \\
\hline & Risk_Management & .116 & .105 & .106 & 1.103 & .273 \\
\hline & Value_Delivery & .438 & .077 & .442 & 5.716 & .000 \\
\hline & Resource_Management & .068 & .056 & .071 & 1.203 & .232 \\
\hline & Performance_Management & .254 & .074 & .254 & 3.433 & .001 \\
\hline
\end{tabular}

Value Delivery $p(0.000)<0.05$, Performance Management $p(0.001)<0.05$, and Strategic Alignment $p(0.089)<0.10$ are statistically significant, but Risk Management $p(0.273)>0.05$ and Resource Management $p(0.232)>0.05$ are not significant.

A result of IT governance model for Japanese SMEs shows the following findings.

H1: There is a significant, positive relationship between IT governance and Strategic Alignment.

$\mathrm{H} 2$ : There is a significant, positive relationship between IT governance and Performance Measurement.

H3: There is positive, but no significant relationships are found between IT governance and Resource Management.

H4: There is positive, but no significant relationships are found between IT governance and Risk Management.

H5: There is a significant, positive relationship between IT governance and Value Delivery.

The results suggest that all hypotheses show positive relationships with IT governance; particularly those with Strategic Alignment, Performance Measurement and Value Delivery are positive and statistically significant.

\section{Conclusions}

Based on literature review on IT governance, the author has tested factors which are related to IT governance, using the survey data from 101 Japanese corporations including large ones and SMEs.

The findings of the ordinal regression analyses in this study indicate that IT governance is associated with Strategic Alignment, Performance Measurement and Value Delivery, while Risk 
Management and Resource Management have positive but no significance association with IT governance.

The results suggest that the corporations recognize that IT strategic alignment as an important component to attain higher levels of IT effectiveness, which in turn could help organizations to obtain better business performance (Luftman at al. 2010). The respondents also seem to understand that measuring IT performance and value delivery are essential parts of any IT governance program.

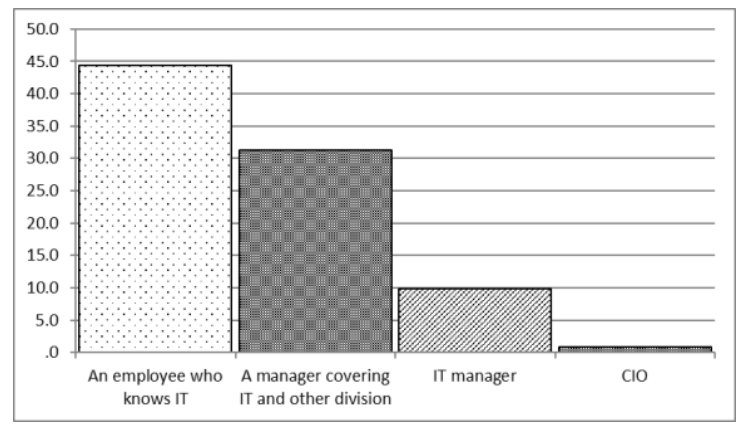

Figure 3. Who is responsible for IT in 2013 [16]

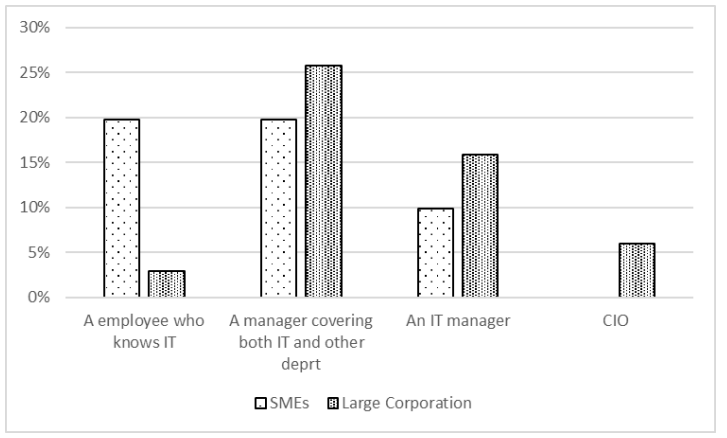

Figure 4. Who is responsible for IT in 2018

However, the author could not find significant associations between IT governance and IT risk and resource management. Although many organizations increasingly recognize the importance of IT governance, it is also known that many of them struggle with implementing and embedding these governance practices into their organization [22].

Results for a question asked, "Who is responsible for IT in your organization?" are shown in figure 3 and figure 4, respectively. Figure 3 reflects the results of questionnaire targeting SMEs in Akita prefecture, the northern part of Japan, conducted in 2013, and figure 4 reflects those of entire Japan, including large companies and SMEs, in 2018. Figure 3 suggests that "an employee who knows IT is responsible for IT" is more than 50 percent, and there are a few CIOs. The result for SMEs in 2018 seems to have the same trend; however, larger corporations have more dedicated IT managers, including CIOs.

The limitation of this study is "sample bias." About one fourth $(24 \%)$ of respondents are representing the telecommunications industry, and $14 \%$ are those of the machinery and electrical equipment, $10 \%$ are representing other manufacturing industry (see Table 2). This paper might have had limited ability to gain access to the appropriate scope of participants. The author is planning to conduct a larger survey research to solve such bias. 


\section{ACKNOWLEDGEMENTS}

This work was supported in part by JSPS Grants-in-Aid for Scientific research (C) Number JP20K01853.

\section{REFERENCES}

[1] Japan Users Association of Information Systems, (2020) "Corporate IT Trend Survey 2020 (FY2019 survey)", Retrieved June 112020 from https://juas.or.jp/library/research_rpt/it_trend/.

[2] HP, (2003) "HP IT Service Management (ITSM), Transforming IT organizations into service providers". Retrieved June 10, 2020 from https://docplayer.net/19185869-Hp-it-service-managementitsm.html.

[3] Schwalbe, Kathy, (2010) Information Technology Project Management, Revised, 6th Edition, Cuorse Technology.

[4] Weill, Peter David \& Ross, Jeanne W., (2004) "IT governance: How Top Performers Manage IT Decision Rights for Superior Results", Harvard Business School, Boston.

[5] Wilbanks, Linda (2008) "IT Management and Governance in Equal Parts", IT Professional, vol. 10, no. 1, Jan./Feb., pp.60-61.

[6] Carroll, Peter, Ridley, Gail \& Young, Judy (2004) "COBIT and its utilization: a framework from the literature", System Sciences, January, pp.233-240.

[7] Webb, Phyl, Pollard, Carol \& Ridley, Gail (2006) "Attempting to Define IT Governance: Wisdom or Folly?" Proceedings of the 39th Hawaii International Conference on System Sciences (HICSS) Vol. 8, ISBN: 0-7695-2507-5, 4-7, January 2006, Hawaii, USA, 194a.-194.1.

[8] Vejseli, Sulejman \& Rossmann, Alexander (2017) "The Impact of IT Governance on Firm Performance A Literature Review", PACIS 2017 Proceedings. 41.

[9] Levstek, Aleš, Hovelja, Tomaž \& Pucihar, Andreja (2018) "IT Governance Mechanisms and Contingency Factors: Towards an Adaptive IT Governance Model", Organizacija 51(4), pp.286-310.

[10] Aasi, Parisa, Rusu, Lazar \& Vieru, Dragos (2017) "The Role of Culture in IT Governance Five Focus Areas: A Literature Review", International Journal of IT/Business Alignment and Governance (IJITBAG), 8(2), pp.42-61.

[11] De Maere, Koen \& De Haes, Steven (2017) "Is the Design Science Approach fit for IT Governance Research?", ECRM 2017 16th European Conference on Research Methods in Business and Management Studies, pp.399-407.

[12] Fink, Kerstin \& Ploder, Christian (2008) "Decision Support Framework for the Implementation of ITGovernance", in Proceedings of the 41st Hawaii International Conference on System Sciences, Los Alamitos, CA: IEEE, Paper 432. 2008.

[13] De Haes, Steven \& Van Grembergen, Wim (2009) "An Exploratory Study into IT Governance Implementations and its Impact on Business/IT Alignment", Information Systems Management, 26, (2), pp.123-137.

[14] Symons, Craig (2005) IT Governance Framework, Forrester Research, Inc.

[15] Lunardi, Guilherme Lerch, Maçada, Antonio Carlos, \& Becker, João Luiz (2017) "Antecedents of IT Governance Effectiveness: An Empirical Examination in Brazilian Firms", Journal of Information Systems 31 (1), pp.41-57.

[16] Miyamoto, Michiko \& Kudo, Shuhei (2013) "Five Domains of Information Technology Governance in Japanese SMEs; An Empirical Study", International Conference on ICT Convergence 2013 (ICTC2013), Proceedings, pp.964-969.

[17] McCullagh, Peter \& Nelder, John A. (1983) Generalized linear models. Second ed. London: Chapman and Hall.

[18] Sharma, Subhash \& Mukherjee, Soumen (1996) Applied Multivariate Techniques, John Wiley and Sons, Inc., New York.

[19] Tabachnick, Barbara G. \& Fidell, Linda S. (2001) Using Multivariate Statistics. Allyn and Bacon A Pearson Education Company Boston.

[20] Johnson, Richard A. \& Wichern, Dean W. (2002) Applied Multivariate Statistical Analysis. Prentice Hall, upper Saddle River, New Jersey.

[21] Draper, Norman Richard \& Smith, Harry (1998) Applied Regression Analysis (Wiley Series in Probability and Statistics), Third Edition, Wiley. 
[22] De Haes, Steven, Van Grembergen, Wim \& Debreceny, Roger S. (2013) "COBIT5 and enterprise governance of information technology: Building blocks and research opportunities." Journal of Information Systems; 27(1): pp. 307-324.

\section{AUTHOR}

Michiko Miyamoto studied at the State University of New York College at Buffalo, where she received her Bachelor of Science degree (magna cum laude). She received her MBA from the University of California at Los Angeles. After a 7-year career with Goldman Sachs and Company, obtained her PhD further to a thesis about Econometrical Approaches to Economic and Strategic Management Studies at the University of Tsukuba, Graduate School of Systems Management. In 2008, she joined the Department of Management Science and Engineering at the Akita Prefectural University.

(C) 2021 By AIRCC Publishing Corporation. This article is published under the Creative Commons Attribution (CC BY) license. 